\title{
珠江三角洲城市群工业生产空间格局、 形态特征及影响因素
}

\author{
丁 俊 ${ }^{1,2,3}$, 王开泳 ${ }^{1,2^{*}}$ \\ (1. 中国科学院地理科学与资源研究所, 北京 $100101 ; 2$. 中国科学院区域可持续发展分析与模拟重点实验室, \\ 北京 100101；3. 中国科学院大学,北京 100049)
}

\begin{abstract}
摘 要:GIS 空间分析技术为空间形态的精准判别提供了新的路径和研究视角。本文通过高分辨率Google Earth 影 像提取 2013 年珠江三角洲城市群的工业生产空间分布信息, 运用分形模型、形态紧凑度、空间离散度、密度指数定 量分析珠三角工业生产空间的形态特征, 采用 GIS 空间分析并结合社会经济统计分析进一步探讨了影响其分布的 主要因素。结果表明: (1)2013 年珠江三角洲城市群的工业生产空间共有 $2604.71 \mathrm{~km}^{2}$, 其空间分布呈现典型的“核 心一边缘” 结构, 并且形成了交错式、零散式和集中式 3 种分布模式。(2)珠江三角洲城市群的工业生产空间具有很 强的分形特征, 核心区的分形维数整体小于外围地区, 而空间结构的稳定性高于外围地区; 珠三角各市中,工业生 产空间形态紧凑度最高的为珠海、最低的为广州, 而空间离散度最高的为惠州、最低的为中山; 珠三角各市工业生 产空间的规模差异显著, 与经济规模、人口规模、工业企业数等呈较强的正相关关系, 而东莞、深圳、中山、佛山的密 度指数过高, 需加强工业生产空间的集约高效利用。(3)自然因素与交通条件、城镇化与开发区的发展、政策的引导 和调控以及经济全球化是珠江三角洲城市群工业生产空间分布的主要影响因素。
\end{abstract}

关 键 词:工业生产空间;空间形态; 空间格局;形态特征; 珠江三角洲城市群

\section{1 引言}

从功能空间的角度, 可把城市空间划分为生产 空间、生活空间和生态空间 3 部分。生产空间是国 家或区域进行产品生产和生产服务的空间载体, 以 工业生产空间为主要表现形式。工业生产是工业 化阶段区域发展的主导力量, 其空间结构与演变反 映了地区工业经济活动及其实体要素的空间格局 和发展演化(夏丽丽等, 2009)。随着工业化和城镇 化的快速推进, 城市群地区的空间不断扩张, 尤其 以工业生产空间的变化最为剧烈, 出现了无序扩 张、用地混杂粗放等问题。在此背景下, 党的十八 大报告明确提出, 要优化国土空间开发格局, 控制 开发强度,调整空间结构,促进“生产空间集约高 效、生活空间宜居适度、生态空间山清水秀”。因
此,促进生产空间尤其是工业生产空间的集约高效 地利用是生态文明建设背景下的一个重要课题。

目前, 国内外学者对工业生产空间的有关内容 已进行了广泛的研究。从研究内容看, 主要包括工 业集聚的区位因素及影响 (Zhu, 2002; Fan et al, 2003; 叶玉瑶等, 2007; Lindsey et al, 2014a, 2014b)、 空间重组(Liao et al, 2011; Tang et al, 2015)、空间分 布与分异(李立勋等, 1997; 叶昌东等, 2010; 曹玉红 等, 2015)、驱动机制 (Scott, 1982; 申庆喜等, 2015), 以及空间内部的产业转移(沈静等, 2012)、产业及土 地利用政策 (方忠权等, 2009; Howland, 2010)等。 从研究方法看, 主要以计量分析为主, 大多通过构 建一定的指标体系或模型来评价区内的工业发展 水平及空间差异(伍世代等, 2011; 曾春水等, 2012; 洪俊杰等, 2014)。近年来,随着 RS 和 GIS 技术的迅

收稿日期: 2015-11; 修订日期: 2016-03。

基金项目: 国家自然科学基金项目(41371178) [Foundation: National Natural Science Foundation of China, No.41371178]。 作者简介: 丁俊(1990-), 男, 云南曲靖人, 硕士生, 主要研究方向为城市地理、城市与区域规划, E-mail: dingj.14s@igsnrr.ac.cn。 通讯作者:王开泳(1980-), 男, 山东滕州人, 副研究员, 主要从事城市地理与行政区划研究, E-mail: wangky@igsnrr.ac.cn。 K Y. 2016. Spatial pattern and morphological characteristics of industrial production space and influential factors in the Pearl River Delta urban agglomeration[J]. Progress in Geography, 35(5): 610-621.]. DOI: 10.18306/dlkxjz.2016.05.008 
速发展, 快速获得大范围的空间信息成为可能,为 土地利用变化和空间演化有关的研究提供了新的 思路和方法, 因此成为地理科学研究的热门领域 (黎夏等, 2009; Kuang, 2012), 少数学者也利用 RS 和 GIS 技术对工业生产空间的开发特征(王智勇等, 2012)、时空演变(德力格尔等, 2014; 郭付友等, 2014)等进行了相关探索。从已有的研究来看, 只 是从计量和统计分析层面对工业生产空间进行过 较多的分析,所刻画的工业生产空间格局较为模 糊, 很难直观地表达工业生产空间的实际分布状 况,而对实体地域及其空间形态研究较少。

珠江三角洲(以下简称珠三角)作为中国改革开 放的先行区及国家的优化开发地区, 经济发达, 工 业实力雄厚, 其城镇化和工业化发展在中国具有典 型性和代表性(许学强等, 2009)。近年来, 伴随土地 资源紧张、劳动力成本上升、资源环境承载力告急 等问题凸显, 珠三角产业结构转型与空间结构调整 迫在眉睫(㚞杰等, 2009), 工业生产空间的优化调控 也成为其面临的迫切而重大的问题。而判别掌握 工业生产空间的真实分布状况, 是对其进行优化调 控并推进集约高效利用的前提和基础。虽然珠三 角的城镇化和工业化一直是学术界研究的热点, 但 研究的重点为珠三角整体的空间结构及土地利用 (张文忠等, 2003; 王开泳等, 2008; Dai et al, 2010), 很少从区域尺度专门对其工业实体空间的分布规 律进行研究, 相关的基础研究, 如工业生产空间的 空间边界与数量、空间形态及特征等也较为缺乏。 为此, 本文利用 RS 和 GIS 技术, 通过高分辨率的 Google Earth 影像对珠三角工业生产空间的实体信 息进行准确判别与提取, 从空间形态学的角度并结 合 GIS 空间分析对珠三角工业生产空间的分布格 局与形态特征进行定性和定量分析, 并在此基础上 进一步揭示影响其分布的主要影响因素, 以便为珠 三角地区生产空间的优化与调控提供决策参考。

\section{2 数据与方法}

\section{1 研究区域概况}

本文所指的珠三角城市群包括广州、深圳、珠 海、佛山、江门、东莞、中山7市和惠州的市辖区、惠 东县、博罗县以及肇庆的市辖区、高要市、四会市, 总面积约 4.17 万 $\mathrm{km}^{2}$ 。2 2013 年, 常住人口为 5715.19 万人, 城镇化率为 $84.03 \%$; 地区生产总值
5.3 万亿元,约占全国经济总量的 $9 \%$; 第二产业增 加值为 2.4 万亿元, 工业总产值达 9.07 万亿元。

\section{2 数据来源与处理}

本文的社会经济统计数据来源于《广东统计年 鉴2014》,空间信息数据主要通过对 2013 年底珠三 角 Google Earth 卫星影像矢量化而来。首先, 利用 Google 卫星地图下载器获取珠三角高分辨率的 Google Earth卫星影像(可看清建筑物); 其次, 通过 ENVY 软件对卫星影像和珠三角行政区划矢量图 进行空间配准,使图像校正的误差控制在半个像元 内; 最后, 将配准后的图像导人 ArcGIS 中, 通过人 工判读和目视解译对工业生产空间进行矢量化。 为获取珠三角较为精准的工业生产空间布局, 本文 矢量化的范围不仅包括集聚的各类工业园区,也包 括大量零散的独立工厂及乡镇工厂。在矢量化过 程中, 大部分工业生产空间能够清晰地识别出来, 个别难以识别或不好确认的区域通过最新的地图 或实地勘察进行校正和补充。通过以上步骤得到 的珠三角城市群工业生产空间分布的矢量图, 经 GIS 空间统计, 工业生产空间总面积为 2604.71 $\mathrm{km}^{2}$, 占整个城市群地区总面积的 $6.25 \%$ 。

运用人工判读和目视解译方法进行工业生产 空间的矢量化处理,虽工作量较大, 但优点也非常 明显,不仅能把集中连片的工业生产空间提取出 来,而且能将那些分散、零碎、边缘的工业生产空间 进行精准提取。珠三角城市群地区乡镇工业尤为 发达, 分布较为零散,利用该方法提取出的工业生 产空间基本接近其实际的分布状况,精确性和实效 性也比一般的遥感图像解译方法高很多。

\section{3 研究方法}

基于 GIS 空间分析技术,通过引人分形模型、 形态紧凑度、空间离散度和密度指数等参数来定性 与定量综合分析珠三角城市群工业生产空间的格 局与形态特征。其中,前 3 个指数分别反映工业生 产空间实体的复杂稳定程度、紧凑程度和离散程 度, 三者相互补充, 充分表达了空间形态的不同侧 面; 密度指数则可进一步反映工业生产空间的开发 强度。各参数的含义及计算方式如下所述。

\subsection{1 分形特征模型}

分形理论广泛应用于城市空间形态(赵萍等, 2003)、城市土地利用分形(贾文臣等, 2009)等方面 的研究。因此,本文引人分形维数来定量分析工业 生产空间的形态特征。分形维数不仅能反映用地 
边界形状的复杂程度, 还能反映用地的破碎程度和 图形的空间填充能力 (王青, 2002)。一般根据斑块 周长和面积之间的关系来计算分形维数, 其关系式 为(杨涵等, 2009):

$$
\ln A=\frac{2}{D} \ln P+C
$$

式中: $A$ 为工业生产空间的斑块面积; $P$ 为斑块总周 长; $C$ 为常数 (截距); $D$ 为分形维数。 $D$ 值的理论值 为 $1.0 \sim 2.0, D$ 值越大, 表示图形形状越复杂, 边界越 不规则, 反之亦然。当 $D=1.5$ 时, 表示斑块图形处于 布朗随机运动状态, 越接近该值, 则稳定性越差。 据此可以定义工业生产空间的稳定性指数 $(S K)$ 如 下(徐建华, 2002):

$$
S K=|1.5-D|
$$

式中: $S K$ 的理论值为 $0 \sim 0.5, S K$ 值越大, 表明工业生 产空间越稳定, 反之亦然。

\subsection{2 形态紧凑度}

形态紧凑度被认为是反映城市空间形态的一 个十分重要的概念(王新生等, 2005), 其计算公式为:

$$
C=2 \sqrt{\pi A} / P
$$

式中: $C$ 为形态紧凑度; $A$ 和 $P$ 同式(1)。 $C$ 值越大, 工业生产空间的形态紧凑性越高; 反之, 形态紧凑 性越低。

\subsection{3 空间离散度}

空间离散度指数是区域差异程度的定量表达， 反映了面状区域上离散点的分布情况。由于珠三 角城市群工业生产空间的单体斑块相对于城市乃 至整个区域的尺度来说非常小, 因此可将其抽象为 区域上的点来研究其空间离散度。衡量空间离散 度的指标有很多(郭仁忠, 2001; 李新运, 2004), 本文 引人加权平均重心距离和加权平均间距 2 个指标来 综合评价。

\section{(1) 加权平均重心距离}

加权平均重心距离反映的是空间点集相对于 分布重心的径向离散程度, 具有长度量纲。设空间 点 $p_{i}\left(x_{i}, y_{i}\right)$ 的属性值为 $a_{i}$, 则点集的分布重心坐标 $\left(x_{\mathrm{g}}\right.$, $\left.y_{\mathrm{g}}\right)$ 为:

$$
\begin{aligned}
& x_{\mathrm{g}}=\sum\left(a_{i} \times x_{i}\right) / \sum a_{i} \\
& y_{\mathrm{g}}=\sum\left(a_{i} \times y_{i}\right) / \sum a_{i}
\end{aligned}
$$

点集到分布重心的加权平均距离为:

$$
\overline{d_{1}}=\sum\left(a_{i} \times d_{i}\right) / \sum a_{i}
$$

式(4)-(6)中: 属性值 $a_{i}$ 为相应工业生产空间的面积; $d_{i}$ 为点 $p_{i}$ 到分布重心的距离; $\overline{d_{1}}$ 为加权平均重心距
离; $i(i=1,2, \ldots, n)$ 为区域内点的数量。

(2) 加权平均间距

由于空间点集既有位置坐标又有属性特征, 因 此点与点之间的相对距离具有不对称性(李新运, 2004)。定义从点 $p_{i}$ 到 $p_{j}$ 的距离为 $d_{i j}$, 从点 $p_{j}$ 到 $p_{i}$ 的 距离为 $d_{j i}$, 即

$$
\begin{aligned}
& d_{i j}=a_{j} \times \sqrt{\left(x_{i}-x_{j}\right)^{2}+\left(y_{i}-y_{j}\right)^{2}} \\
& d_{j i}=a_{i} \times \sqrt{\left(x_{i}-x_{j}\right)^{2}+\left(y_{i}-y_{j}\right)^{2}}
\end{aligned}
$$

则点集之间的加权平均间距为:

$$
\overline{d_{2}}=\sum_{i} \sum_{j} d_{i j} / \sum\left(n \times a_{i}\right)
$$

式中: $\overline{d_{2}}$ 为加权平均间距 $; i 、 j(i=1,2, \ldots, n ; j=1$, $2, \ldots, n ; i \neq j)$ 为区域内点的数量。

(3) 空间离散度

由于 $\bar{d}_{1}$ 和 $\overline{d_{2}}$ 对空间离散度的贡献程度差不 多, 故采用等权重的方法对其赋权 (李贺颖等, 2014)。利用Z-score标准化方法分别对 $\overline{d_{1}}$ 和 $\overline{d_{2}}$ 进 行标准化处理为 $d_{1}$ 和 $d_{2}$, 最终利用式(10)计算得到 空间离散度 $D C I$ 。DCI 数值越大, 工业生产空间分 布越离散; 反之亦然。

$$
D C I=\left(d_{1}+d_{2}\right) / 2
$$

\subsection{4 密度指数}

密度指数即工业生产空间面积与城市总面积 的比值, 反映了工业生产空间的开发强度,计算公 式如下:

$$
\rho=\left(A / A_{0}\right) \times 100 \%
$$

式中: $\rho$ 为密度指数; $A$ 为工业生产空间面积; $A_{0}$ 为 城市总面积。

\section{3 珠三角城市群工业生产空间的总体 分布格局与形态特征}

\section{1 总体分布格局}

改革开放以来, 珠三角城市群通过 “三来一补” 和发达的乡镇企业率先实现自下而上的工业化和 城镇化, 形成了许多高度专业化的工业城镇, 工业 遍地开花, 呈现 “村村点火,户户冒烟” 的全域式工 业化景象。经过30多年的发展,珠三角城市群工业 生产空间逐渐形成了特有的分布格局。从区域的 总体布局可以直观看出(图 1), 珠三角城市群的工业 生产空间在珠江人海口两岸分布最为密集,并形成 了集中连片的发展态势, 体现了珠三角城市群一体 
化的发展趋势。而在珠三角城市群的外围地区, 工 业生产空间分布较为零散, 只在一些区位条件较好 或重要的交通沿线呈小规模集聚。另外, 珠三角城 市群的工业生产空间大多围绕城市核心节点进行 空间布局, 距离城市核心节点越近,工业生产空间 分布越集中, 规模越大; 距离城市核心节点越远, 工 业生产空间分布则相对松散。总体上看, 珠三角城 市群工业生产空间的分布格局呈现出比较典型的 “核心一边缘”结构, 内圈层为工业生产空间密集 区,外圈层为工业生产空间松散带。

珠三角城市群的工业生产空间与城市生活空 间、生态空间相互交织和相互影响, 根据三者之间 的空间关系, 可将其归纳为以下 3 种空间分布模式 (图2):

模式 I : 交错分布模式。这类模式的主要特点 是工业生产空间与生活空间、生态空间交错分布, 3 种空间的面积比例相差不大, 均呈集中连片的发展

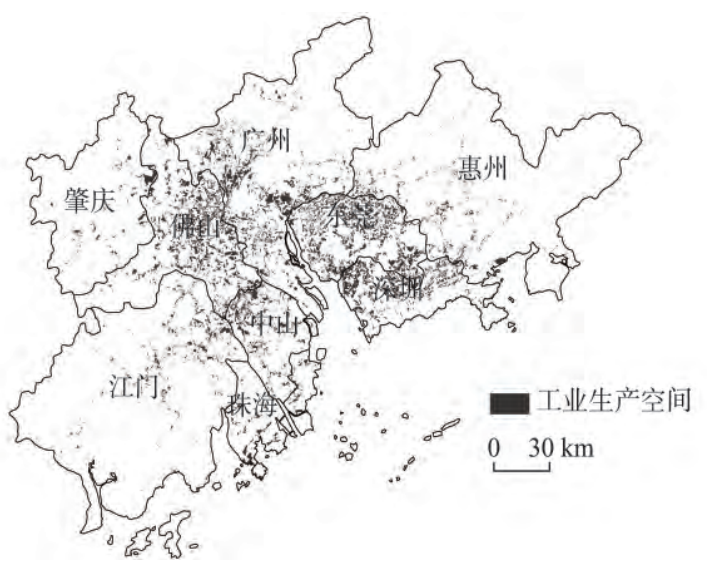

图 1 珠三角城市群工业生产空间总体分布图

Fig.1 Overall distribution of industrial production space in the Pearl River Delta region
态势,主要位于城市核心区的周边。在这类分布模 式中,工业生产空间往往与城市郊区的居住区、生 态绿地等相邻,并且距离城市中心区较近,一些“三 高”工业企业的存在,在一定程度上会给生活环境 和生态环境造成污染, 影响城市的人居环境和可持 续发展。在城市群空间的优化调控中, 对于这类空 间分布模式应重点协调好生产、生活、生态三者之 间的比例与空间分布关系, 促进其协调发展。

模式 II :零散分布模式。这类模式主要位于珠 三角城市群核心区的外围, 以森林、农田等大面积 的生态空间为主体,工业生产空间的规模较小, 沿 高速公路、国道、省道等主要交通干道两侧零散分 布, 多为镇办或村办的小型工厂。这类工业生产空 间没有经过统一的规划和规范的管控, 占用农用 地、林地等现象非常普遍，不仅用地粗放、效率低 下、呈破碎化分布, 而且在一定程度上给当地造成 了空气污染、水体污染和土壤污染。

模式 III : 集中分布模式。这类模式多为大中型 开发区,城市核心区周边或外围均有分布, 以工业 生产空间为主体,生活空间、生态空间(多为绿地)、 空地零散分布。此类型也反映出了开发区的内部 结构特征和土地的利用程度。珠三角城市群有众 多的开发区和工业园区,大部分开发区呈现规模化 布局,空间形态较为紧凑集中。但也有一些开发区 存在盲目圈地的现象, 产业用地较为粗放, 大片土 地空置, 利用效率较低。

\section{2 形态特征}

\subsection{1 分形特征}

利用ArcGIS 10.0 提取 2013 年珠三角城市群各 市工业生产空间各斑块的面积 $(A)$ 与周长 $(P)$ 的属性 值, 利用 SPSS 对各市工业生产空间的斑块周长一 面积双对数绘制散点图, 并进行线性回归分析, 进
模式 I：交错分布模式

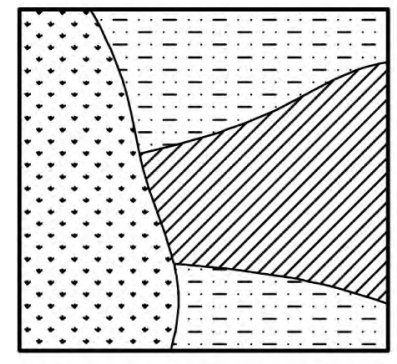

पIIIIA 工业生产空间
模式 II : 零散分布模式

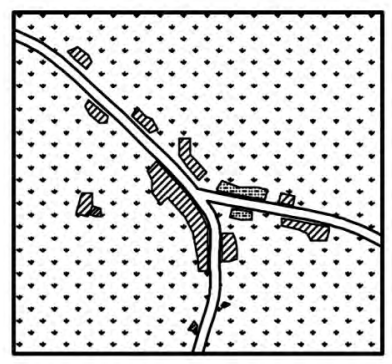

$\because \because$ 生态空间
模式 III：集中分布模式

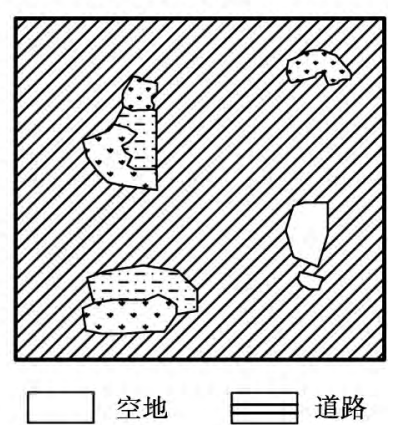

图 2 珠三角城市群工业生产空间分布模式

Fig.2 Spatial distribution patterns of industrial production space in the Pearl River Delta region 
而根据式(1)和式(2)计算得到各市工业生产空间的 分形维数和稳定性指数(表 1 )。分析可知, 各市工业 生产空间的周长 $(P)$ 一面积 $(A)$ 关系模型的相关系数 均较高, 并且通过了显著性检验, 说明具有很强的 分形特征。

2013 年珠三角城市群各市工业生产空间分形 维数最大的城市为肇庆, 其次为江门和惠州, 表明 其空间结构较为复杂, 工业生产空间分布较为破 碎; 分形维数最小的城市为东莞, 其次为佛山和珠 海, 表明其空间结构相对简单, 工业生产空间分布 相对规整。由此可见,珠三角城市群核心区工业生 产空间的分形维数整体小于外围地区。这是由于 珠三角城市群核心地区的工业化和城镇化水平较 高, 城市建设用地较为紧张, 许多工业生产空间得 到了统一规划而使其边界相对整齐、规则; 而外围 地区工业化和城镇水平相对较低, 并处于快速发展 时期,工业生产空间规模小且分布杂, 呈现快速扩 张趋势, 使其边界形状较为复杂且不规则。

从稳定性指数来看, 2013 年工业生产空间结构 最稳定的是东莞, 其次为佛山和珠海; 而工业生产 空间结构最不稳定的是肇庆,其次为江门和惠州。 这与分形维数的排序正好相反, 一方面表明珠三角 城市群核心地区工业生产空间受规划控制和建设 用地紧张的影响, 其空间结构较为稳定; 另一方面 也表明核心区工业生产空间用地扩张态势减缓, 空 间范围相对稳定, 而外围地区的工业生产空间处于 快速扩张阶段而使其空间结构不稳定。

\subsection{2 形态紧凑性与空间离散程度}

根据式(3)计算得到珠三角城市群各市工业生 产空间的形态紧凑度(表 2), 结果表明: 珠三角城市 群工业生产空间整体的形态紧凑性不高, 范围在
0.0200 0.0697之间。其中,形态紧凑度最高的为珠 海, 最低的为广州, 说明珠海工业生产空间外围轮 廓的形态较为紧凑, 而广州工业生产空间外围轮廓 的形态较为分散。

根据式(4)-(10)计算得到珠三角城市群各市工 业生产空间的空间离散度(表2), 结果表明: 惠州工 业生产空间的空间离散度最高, 其次为广州和江 门, 表明其工业生产空间分布较为离散; 而中山工 业生产空间的空间离散度最低, 其次为珠海和深 圳, 表明其工业生产空间分布相对集中。由于惠 州、江门的地域空间较大, 除靠近珠三角城市群核 心区有少量集中分布外,其余工业生产空间主要沿 外围地区的交通干道零散分布,使得其空间离散程 度较高; 广州南部的工业生产空间分布相对集中, 但其北部由于地形等影响,工业生产空间分布较为 零散且稀少, 使得其整体的空间离散程度较高。而 中山、珠海和深圳均位于珠三角城市群核心地区, 地域空间相对较小且城市建设用地较为紧张, 工业 生产空间的分布相对集中。可以看出,珠三角城市 群核心地区工业生产空间的空间离散度较低,而外 围地区工业生产空间的离散度较高。

\subsection{3 密度与规模特征}

利用ArcGIS 10.0 对珠三角城市群各市工业生 产空间的规模进行空间统计,并根据式(11)计算得 到工业生产空间的密度指数(图 3)。从工业生产空 间的规模来看, 珠三角的工业生产空间共有 $2604.71 \mathrm{~km}^{2}$ 。其中, 佛山的规模最大, 为 525.24 $\mathrm{km}^{2}$; 肇庆的规模最小, 为 $74.66 \mathrm{~km}^{2}$ 。广州、佛山、深 圳、东莞 4 市的工业生产空间规模占整个珠三角的 $70.65 \%$ 。可以看出,珠三角各市工业生产空间的规 模差异显著。进一步利用SPSS 对珠三角各市 2013

表 12013 年珠三角城市群各市工业生产空间分形维数与稳定性指数

Tab.1 Fractal dimensions and stability indices of industrial production space of cities in the Pearl River Delta region in 2013

\begin{tabular}{ccccc}
\hline 城市 & 斑块数 $/$ 个 & 周长 $(P)$ 一面积 $(A)$ 关系模型 & 相关系数 $r$ & 分形维数 $D$ \\
\hline 广州 & 1859 & $\ln A=1.8727 \ln P-2.3413$ & 0.9098 & 1.0680 \\
佛山 & 1569 & $\ln A=1.9339 \ln P-2.7536$ & 0.9377 & 0.4320 \\
肇庆 & 250 & $\ln A=1.7527 \ln P-1.2625$ & 0.9831 & 0.4658 \\
深圳 & 970 & $\ln A=1.8932 \ln P-2.4360$ & 0.8836 & 1.1411 \\
东莞 & 1635 & $\ln A=1.9822 \ln P-3.1968$ & 0.8991 & 1.0564 \\
惠州 & 1043 & $\ln A=1.8038 \ln P-1.7002$ & 0.9148 & 1.0090 \\
珠海 & 214 & $\ln A=1.9010 \ln P-2.5133$ & 0.4910 & 1.1088 \\
中山 & 761 & $\ln A=1.8571 \ln P-2.2528$ & 0.9178 & 0.3912 \\
江门 & 1025 & $\ln A=1.7646 \ln P-1.4556$ & 0.9017 & 0.4479 \\
\hline
\end{tabular}


年的工业生产空间规模与工业总产值、经济规模、 人口规模、工业增加值和工业企业数进行相关分析 (表 3), 结果表明:工业生产空间规模与各指标均呈 正相关关系, 并且与工业企业数、工业总产值、人口 规模和工业增加值显著相关。这说明工业生产空 间与各指标间存在相关促进的关系,工业生产空间 规模的扩大可以促进工业产值的提高和经济的增 长, 工业企业数量的增加和人口的集聚在一定程度 上也会促进工业生产空间规模的扩大。

从工业生产空间的密度指数来看, 东莞最高, 达 $21.85 \%$, 深圳次之 $(16.56 \%)$, 中山(13.41\%)和佛山 (13.29\%)也相对较高; 而肇庆最小, 为 $1.83 \%$ 。由此 也可以反映出东莞、深圳、中山、佛山的开发强度过 高。尤其是东莞, 仅是工业生产空间就占总面积的 $21.85 \%$, 再加上生活空间, 其开发强度早已超过 $30 \%$ 。按照国际惯例,一个地区国土开发强度的警 戒线为 $30 \%$, 超过该强度, 人的生存环境就会受到 影响。而事实上, 东莞、深圳、中山、佛山的国土开 发强度已超过了国际警戒线, 珠海、广州也已逼近 该强度。珠三角城市群土地开发与需求的矛盾已 十分尖锐, 在以后的国土空间开发中应以盘活存量 为主, 提高土地的集约利用效率。

表 22013 年珠三角城市群各市工业生产空间 形态紧凑度与空间离散度

Tab.2 Compact ratios and discrete degrees of industrial production space of cities in the Pearl River Delta region in 2013

\begin{tabular}{ccccc}
\hline 城市 & $\begin{array}{c}\text { 紧凑度 } \\
C\end{array}$ & $\begin{array}{c}\text { 加权重心 } \\
\text { 距离 } / \mathrm{km}\end{array}$ & $\begin{array}{c}\text { 加权平均 } \\
\text { 距离 } / \mathrm{km}\end{array}$ & $\begin{array}{c}\text { 空间离散度 } \\
D C I\end{array}$ \\
\hline 广州 & 0.0200 & 24.41 & 35.64 & 1.1483 \\
佛山 & 0.0219 & 20.08 & 27.89 & -0.2143 \\
肇庆 & 0.0621 & 20.62 & 29.30 & -0.0011 \\
深圳 & 0.0272 & 18.54 & 26.14 & -0.5998 \\
东莞 & 0.0204 & 20.64 & 27.90 & -0.1336 \\
惠州 & 0.0277 & 27.47 & 38.21 & 1.8292 \\
珠海 & 0.0697 & 17.10 & 23.88 & -1.0222 \\
中山 & 0.0312 & 15.02 & 21.16 & -1.5800 \\
江门 & 0.0278 & 22.41 & 32.61 & 0.5735 \\
\hline
\end{tabular}

4 珠三角城市群工业生产空间形成的 主要影响因素

作为改革开放的前沿阵地, 珠三角城市群工业 生产空间的大规模集聚具有一定的特殊性,其当前 的分布格局与形态特征是自然/空间因子及政治、经 济、社会等人文因子共同作用的结果(间小培等, 2006; 叶玉瑶等, 2010)(图 4)。总体而言, 自然基础 和交通条件为珠三角城市群工业生产空间的形成 和布局奠定了基础框架, 提供了空间载体; 城镇化 和开发区的设置则为工业生产空间的布局提供了 根本动力, 并连锁性带动周边地区用地向工业生产 空间转变; 政策引导与调控规定了工业生产空间的 发展方向,并影响其开发进程; 经济全球化和要素 流动是工业生产空间大规模集聚的外部动力, 也为 工业生产空间的扩展提供了外部环境。

\section{1 自然因素与交通条件}

自然条件是珠三角城市群工业生产空间产生 和形成的空间载体,地形和地貌条件不仅影响工业 生产空间分布的基本框架,也影响其区位选择和开 发次序,具有明显的空间指向性(叶玉瑶等, 2010)。 珠江三角洲是一个发育在海湾内的丘陵性三角洲, 地形以平原为主,其间山丘散布, 河道纵横。珠三 角的地势北高南低,核心区主要是地势低平的平原 和河谷地带, 外围则以山地和丘陵为主, 形成了一

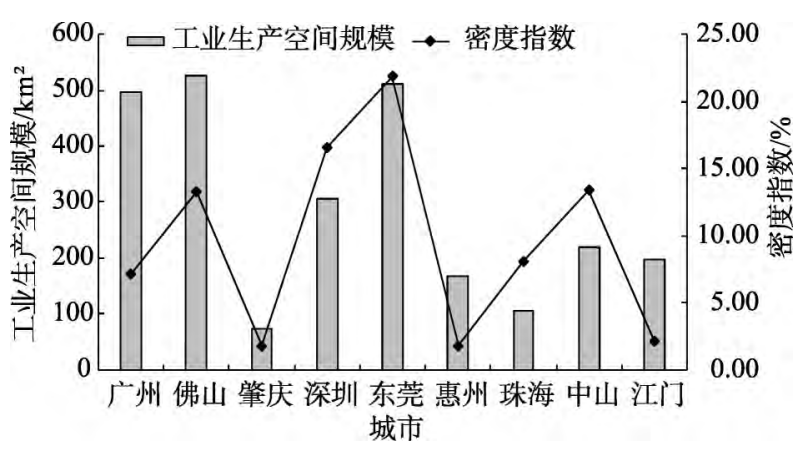

图 3 珠三角城市群各市工业生产空间规模和密度指数

Fig.3 Scale and density index of industrial production space of cities in the Pearl River Delta region

表 3 工业生产空间规模与不同指标的相关分析

Tab.3 Correlation analysis between the scale of industrial production space and other indices

\begin{tabular}{cccccc}
\hline 指标 & 工业总产值 & 经济规模 & 人口规模 & 工业增加值 & 工业企业数 \\
\hline 相关系数 & $0.722^{*}$ & 0.634 & $0.763^{*}$ & $0.681^{*}$ & $0.863^{* *}$ \\
Sig. & 0.028 & 0.067 & 0.017 & 0.044 & 0.003 \\
\hline
\end{tabular}

注:*表示在 0.05 水平上显著相关; **表示在 0.01 水平上显著相关。 


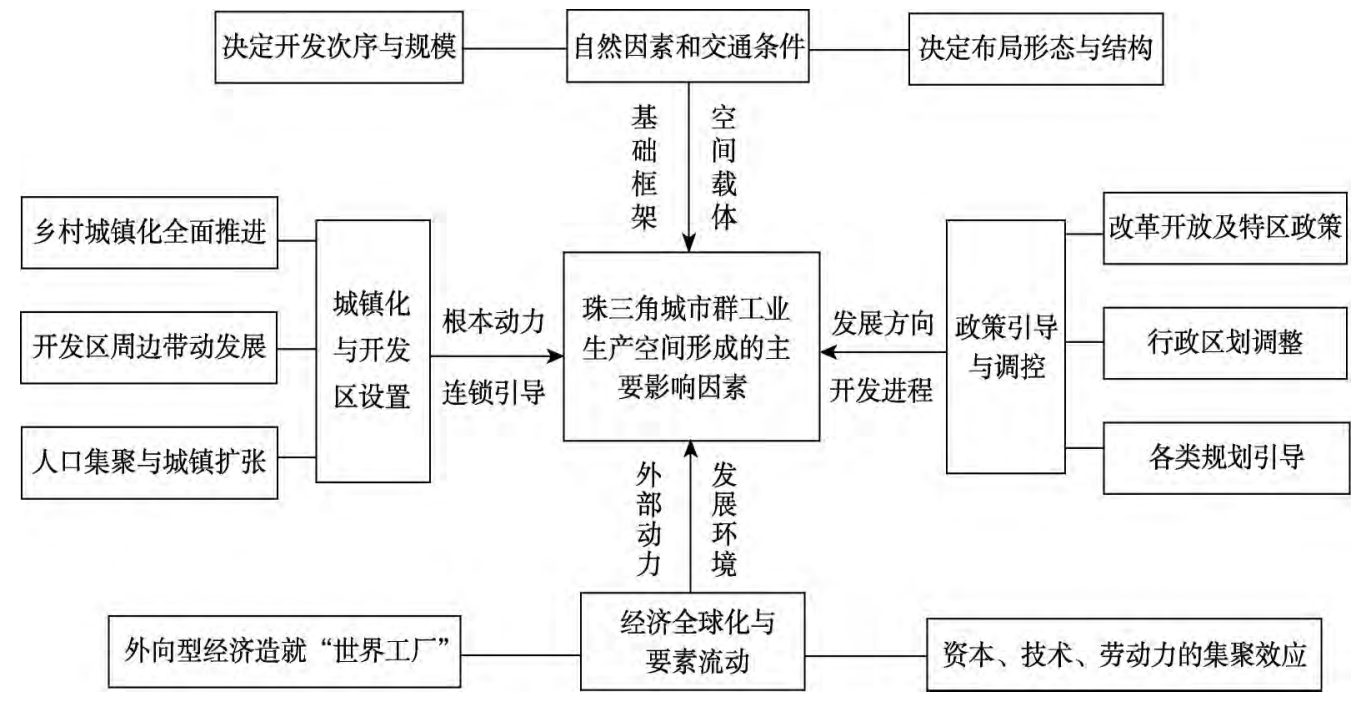

图 4 珠三角城市群工业生产空间形成的主要影响因素

Fig.4 Influencing factors of industrial production space formation in the Pearl River Delta region

个相对闭合的空间格局。受地形条件的影响, 珠三 角城市群的工业生产空间基本上分布于地形平坦、 海拔较低的平原和浅山地带(图 5), 以方便工业生产 活动的合理布局和人们的生活与交通。此外,工业 生产需要大量的用水,珠江作为珠三角地区的主要 河流,也对工业生产空间的分布产生重要影响。利 用 ArcGIS 10.0 对珠江干流进行缓冲分析和叠置分 析(图6), 结果表明: 在珠江干流两侧 $5 \mathrm{~km}$ 范围内分 布的工业生产空间达 $951.31 \mathrm{~km}^{2}$, 占总面积的 $36.52 \%$ 。

珠三角城市群的工业生产空间与主要交通干 道有着紧密的共生关系。良好的交通条件很容易 形成具有竞争力的区位优势, 吸引产业和人口集 聚, 尤其是在一些主要交通干道的两侧, 工业生产

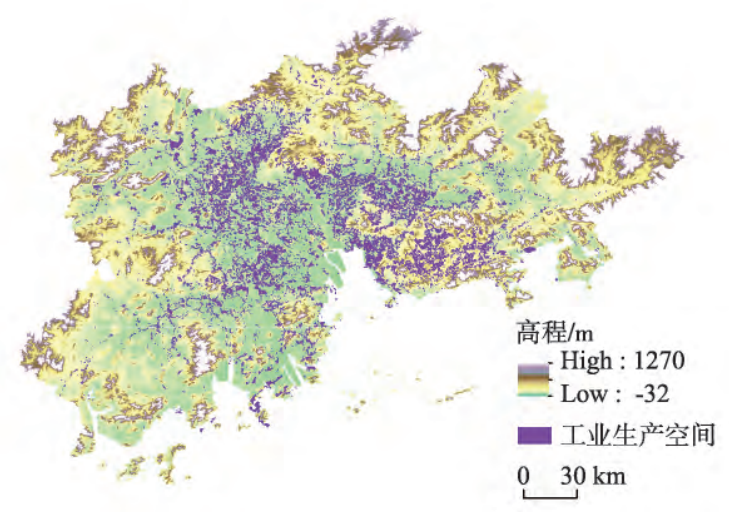

图 5 珠三角地形与工业生产空间分布图

Fig.5 Industrial production space and topography of the Pearl River Delta region
空间分布最为密集。以高速公路为例, 利用软件 ArcGIS 10.0 对其进行缓冲分析和叠置分析(图 7), 研究发现, 在高速公路两侧 $2 \mathrm{~km}$ 范围内分布的工业 生产空间 $1041.79 \mathrm{~km}^{2}$, 占工业生产空间总面积的 $40 \%$; 而在高速公路两侧 $5 \mathrm{~km}$ 范围内分布的工业生 产空间 $1870.66 \mathrm{~km}^{2}$, 占工业生产空间总面积的比例 高达 $71.82 \%$ 。可以看出, 交通条件对珠三角城市群 工业生产空间的分布具有较强的导向作用。

\section{2 城镇化及开发区的带动效应}

城镇化过程与工业生产空间组织既同步变化 又相互影响(许学强等, 2009)。改革开放以来, 珠三 角地区通过自下而上的工业化有力推动了城镇化 的进程, 而城镇化的发展也为工业生产空间的布局 提供了根本动力, 并影响其空间形态。对珠三角各

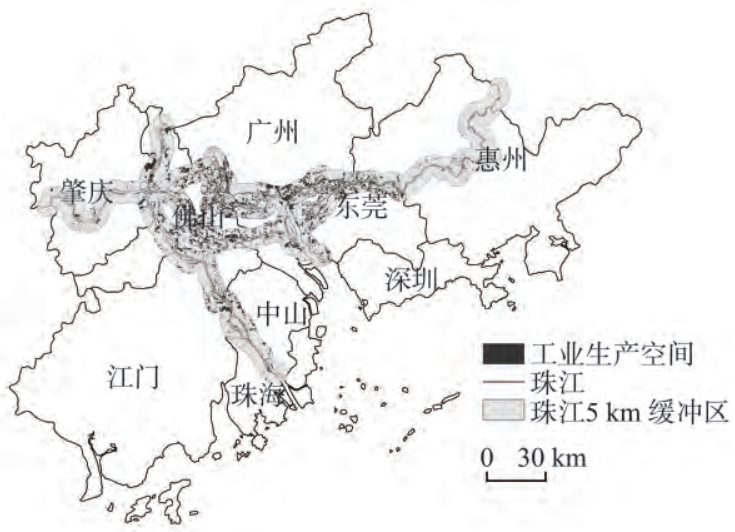

图 6 珠江干流 $5 \mathrm{~km}$ 缓冲区内的工业生产空间

Fig.6 Industrial production space within the $5 \mathrm{~km}$ buffer on both sides of the Pearl River 
地区的城镇化率与分形维数进行曲线拟合(图 8), 结 果表明: 城镇化率与分形维数呈现指数变化关系, 工业生产空间的分形维数随城镇化率的提高呈指 数缓慢下降。一方面, 这说明随着城镇化水平的提 高,工业生产空间的空间形态趋于规则和稳定; 另 一方面,这也印证了前文珠三角城市群工业生产空 间分形特征的结果, 即珠三角城市群核心区的城镇 化率高于外围地区, 而分形维数小于外围地区。

近年来, 随着工业化和城镇化进程的快速推 进,各类开发区作为工业企业的空间载体快速兴 起, 并得到大规模开发建设, 不仅加速了城市空间 的扩张,而且也带动了工业生产空间的集聚与扩 散。截至 2013 年底, 珠三角城市群共有 27 个各类 国家级开发区, 20 个各类省级开发区, 以及上百个 市级工业园区(图9)。可以看出,许多工业企业均在 各类开发区和工业园区集聚发展,工业生产空间的

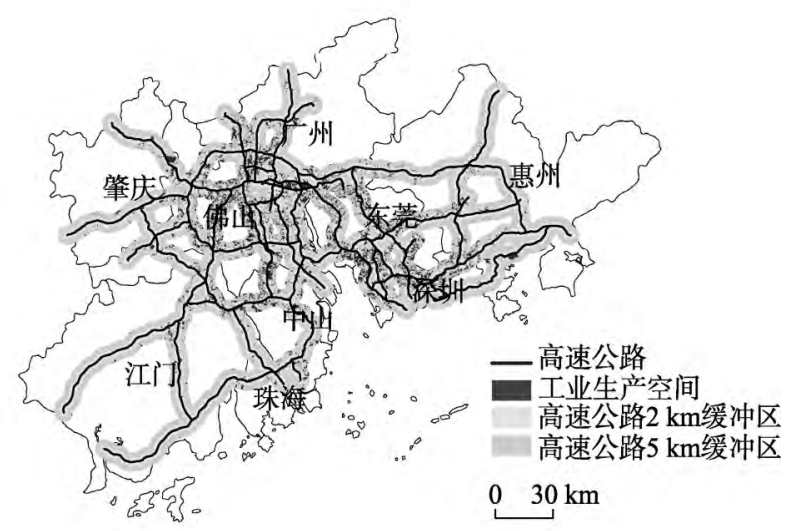

图 7 珠三角城市群高速公路 $2 \mathrm{~km}$ 和 $5 \mathrm{~km}$ 缓冲区内的工业生产空间

Fig.7 Industrial production space within the $2 \mathrm{~km}$ and $5 \mathrm{~km}$ buffers of highways in the Pearl River Delta region

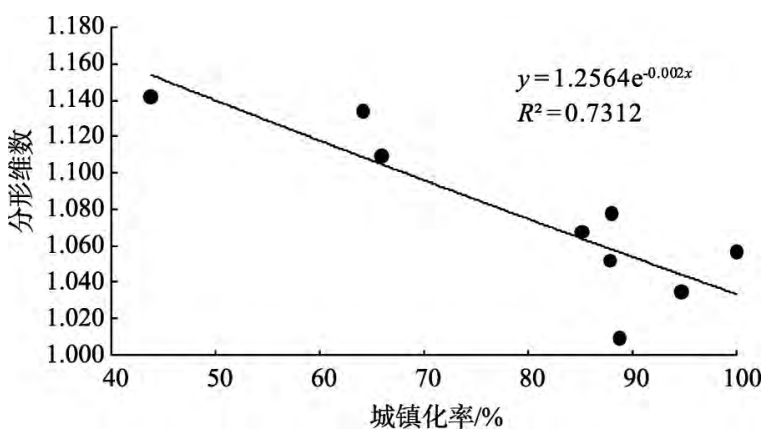

图 8 珠三角地区工业生产空间与城镇化率的曲线拟合

Fig.8 Fitting curve of industrial production space and urbanization rate of the Pearl River Delta region
集聚状态也与开发区和工业园区的区位保持一致。

\section{3 政策的引导和调控作用}

政策的引导和调控对珠三角城市群工业生产 空间的形成影响巨大。率先推行的改革开放政策 为珠三角地区带来了良好的发展机遇, 以土地为载 体吸引了大量的“三来一补”企业和“三资”企业,并 通过“前店后厂”的发展模式(Sit, 1998), 极大促进了 乡镇企业和地方工业的发展, 形成了范围广阔的工 业生产空间。深圳与珠海的特区制度及其招商引 资政策, 以及各市优惠的人口和土地政策, 也吸引 了大量产业集聚,逐渐形成了珠三角地区工业生产 空间的区域布局。地方政府为了各自的发展目标 与竞合关系,通过城市规划手段及产业发展政策对 工业布局进行干预, 从而影响工业生产空间的发展 方向与空间形态。另外, 从城市内部来看,一些重 大工业项目的布局和行政区划调整也影响了工业 生产空间的分布(叶昌东等, 2010)。例如 2000 年, 广州提出“南拓”发展战略后, 包括广州钢铁厂在内 的许多项目纷纷南迁, 推动了广州南部工业的发 展; 2005 年广州新设南沙区、萝岗区作为工业集聚 区, 加快发展步伐, 促进了两地工业生产空间的 集聚。

\section{4 经济全球化的影响}

经济全球化作为一种经济发展潮流深刻影响 着世界范围内的经济联系与空间格局。改革开放 以来,珠三角地区凭借良好的区位优势和政策环境 吸引了大量外资(Yang, 2006), 并通过劳动力成本和 土地成本低廉的比较优势, 极大地促进了制造业的 发展,成为了全球最大的制造业生产基地和名副其

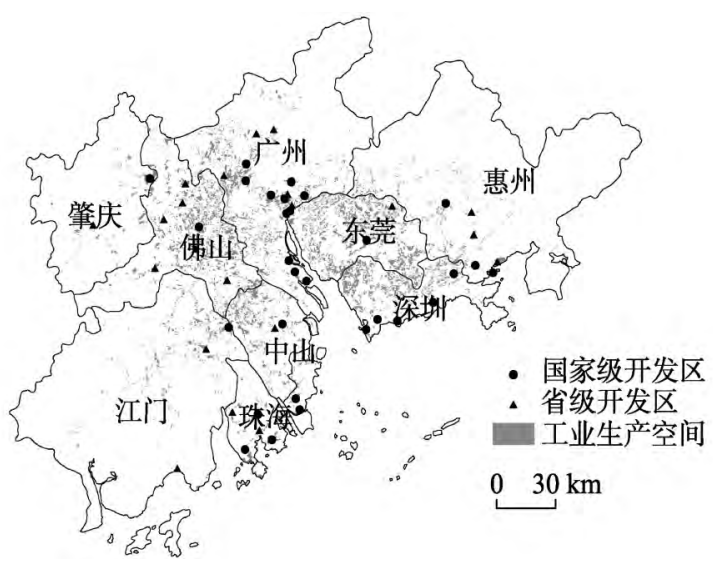

图 9 珠三角城市群各类国家级和省级开发区分布图

Fig.9 Distribution of national-level and provincial-level development zones in the Pearl River Delta region 
实的“世界工厂”(李燕等, 2013)。外商投资将全球 的资金、人才、管理技术等输送到珠三角产业的各 个生产和服务环节, 推动并促进了工业企业的发展 和集聚, 间接影响了工业生产空间的布局与调整, 尤其是香港与珠三角地区跨行政区紧密的经济联 系对珠三角地区的工业格局影响深远(Lin, 1997; Smart et al, 2004)。从实际利用外资的空间分布来 看(图 10), 珠三角地区的外商直接投资主要集中于 靠近珠江人海口岸的核心地区。若将图 10 和图 1 进行对比, 可直观地看出, 珠三角地区外资利用与 工业生产空间的分布具有十分相似的空间特征。 由此可见, 外资的流向对于珠三角城市群工业生产 空间的集聚具有重要的影响。

\section{5 结论与讨论}

\section{1 结论}

本文利用 RS 和 GIS 技术准确判别与提取了珠 三角城市群工业生产空间的实体信息, 从空间形态 学的角度对其分布格局与形态特征进行了定性与 定量分析, 并进一步揭示了影响其分布的主要因 素。主要结论如下:

（1）2013 年珠三角城市群的工业生产空间总规 模为 $2604.71 \mathrm{~km}^{2}$ 。工业生产空间总体上呈现“核心 一边缘”的结构特征, 在珠三角城市群内圈层分布 较为密集, 外圈层则相对松散。工业生产空间与城 市生活空间、生态空间相互交织,形成了 3 种不同的

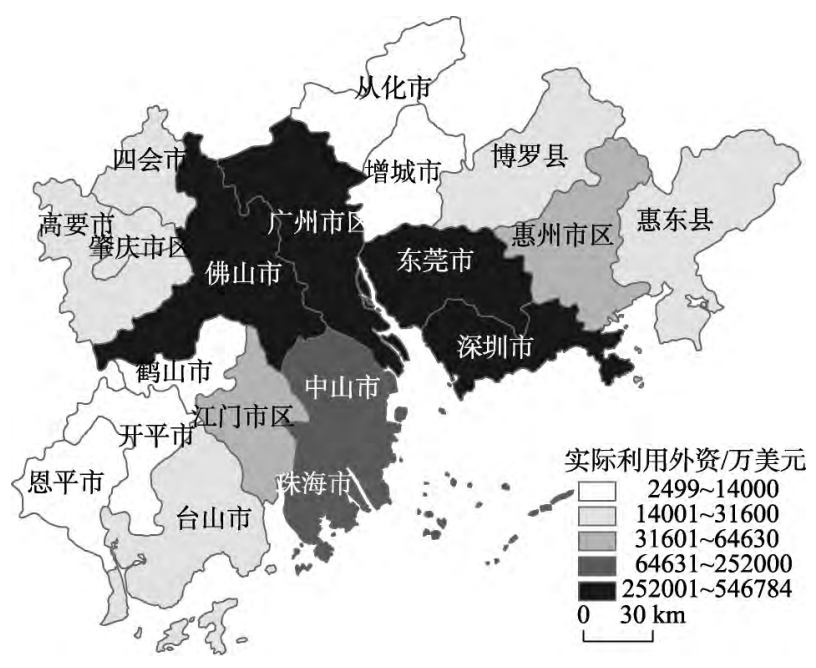

图 102013 年珠三角地区各区县外商直接投资空间分异图

Fig.10 Foreign direct investment by county in the Pearl River Delta region in 2013
空间分布模式,分别是交错分布模式、零散分布模 式和集中分布模式。

(2) 珠三角城市群工业生产空间具有很强的分 形特征,核心区的分形维数整体小于外围地区,而 空间结构的稳定性高于外围地区。珠三角城市群 各市中,工业生产空间形态紧凑度最高的为珠海、 最低的为广州, 而空间离散度最高的为惠州、最低 的为中山。珠三角各市工业生产空间的规模差异 显著, 与经济规模、人口规模、工业企业数等呈较强 的正相关, 而东莞、深圳、中山、佛山的密度指数过 高,在今后的发展中应注意控制增量。

(3) 珠三角城市群工业生产空间的形成与分布 具有一定的特殊性, 主要受自然因素与交通条件、 城镇化和开发区的发展、政策的引导和调控以及经 济全球化等因素影响。

\section{2 讨论}

工业生产空间的分布是由特定发展阶段决定 的,作为改革开放的前沿, 珠三角地区的工业化的 确带动了整个区域的发展,但也存在工业生产空间 用地粗放、密度过高等问题。在经济全球化和新型 城镇化背景下, 全球出口压力增大、劳动力成本上 升、环境质量要求越来越严格等问题使得珠三角地 区原来粗放式的发展方式难以为继。未来应严格 控制珠三角城市群工业生产空间的量的增长,并更 加关注质的提升, 加快推进传统工业企业的转型升 级, 优化调控工业生产空间的布局, 塑造更加集约 高效的生产空间分布格局。而要对工业生产空间 进行优化调控, 判别掌握其真实分布状况既是前提 也是基础。本文通过 RS 和 GIS 技术弄清了珠三角 城市群工业生产空间规模、空间分布及空间形态特 征等问题,这对于下一步进行工业生产空间的优化 调控具有重要的参考价值。

当然, 不足的是, 由于图像处理的工作量较大, 本文主要是静态的研究,未来将进一步增加时间维 度探讨其空间演化过程及机理。生产空间的优化 调控已经纳人国家战略,但在研究层面的相关成果 相对较少, 对于生产空间的优化调控和空间政策研 究也亟需加强。另外, 生产空间是一个内涵较为广 泛的概念, 其类型不仅包括工业生产空间, 还有仓 储物流空间、农业生产空间等,各类生产空间之间 的关系如何,工业生产空间与城市生活空间和生态 空间之间如何协调? 这些均是今后需要深人研究 的课题。 


\section{参考文献(References)}

曹玉红, 宋艳卿, 朱胜清, 等. 2015. 基于点状数据的上海都 市型工业空间格局研究 [J]. 地理研究, 34(9): 17081720. [Cao Y H, Song Y Q, Zhu S Q, et al. 2015. The spatial pattern of Shanghai urban industry based on point data [J]. Geographical Research, 34(9): 1708-1720.]

德力格尔, 袁家冬, 李媛媛. 2014. 长春市工业空间格局时空 演变特征 [J]. 经济地理, 34(11): 81-86. [Deligeer, Yuan J D, Li Y Y. 2014. The spatial-temporal evolution characteristics of the industrial spatial in Changchun[J]. Economic Geography, 34(11): 81-86.]

焚杰, 陈东. 2009. 珠江三角洲产业结构转型与空间结构调 整的战略思考 [J]. 中国科学院院刊, 24(2): 138-144.

[Fan J, Chen D. 2009. Strategic consideration on the industrial structure transformation and spatial structure adjustment in Pearl River Delta[J]. Bulletin of Chinese Academy of Sciences, 24(2): 138-144.]

方忠权, 余国扬. 2009. 珠江三角洲产业空间协调的政策取 向 [J]. 热带地理, 29(6): 539-543. [Fang Z Q, Yu G Y. 2009. Policy orientation of industrial spatial coordination in the Pearl River Delta[J]. Tropical Geography, 29(6): 539-543.]

郭付友, 陈才, 刘继生. 2014. 1990年以来长春市工业空间扩 展的驱动力分析 [J]. 人文地理, (6): 88-94. [Guo F Y, Chen C, Liu J S. 2014. Research on the extension characteristics and driving forces of industrial space in Changchun since 1990[J]. Human Geography, (6): 88-94.]

郭仁忠. 2001. 空间分析 [M]. 2 版. 北京: 高等教育出版社.

[Guo R Z. 2001. Spacial analysis[M]. 2nd ed. Beijing, China: Higher Education Press.]

洪俊杰, 刘志强, 黄薇. 2014. 区域振兴战略与中国工业空间 结构变动: 对中国工业企业调查数据的实证分析 $[\mathrm{J}]$. 经 济研究, (8): 28-40. [Hong J J, Liu Z Q, Huang W. 2014. Regional revitalization strategies and the industrial spatial structure changes in China: Evidence based on China industrial survey database[J]. Economic Research Journal, (8): 28-40.]

贾文臣, 贾香云, 李福印, 等. 2009. 威海市土地利用分形特 征动态变化 [J]. 地理科学进展, 28(2): 193-198. [Jia W C, Jia X Y, Li F Y, et al. 2009. Dynamic changes of land use fractal characteristic in Weihai, China[J]. Progress in Geography, 28(2): 193-198.]

黎夏, 叶嘉安. 1999. 基于遥感和 GIS 的辅助规划模型: 以珠 江三角洲可持续土地开发为例 [J]. 遥感学报, 3(3): 215219. [Li X, Yeh A G. 1999. A planning support model for sustainable land development using remote sensing and GIS: A case study in the Pearl River Delta[J]. Journal of Remote Sensing, 3(3): 215-219.]
李贺颖, 王艳慧. 2014. 贫困县村级居民点空间分布离散度 与农村居民纯收人关联格局分析[J]. 地理研究, 33(9): 1617-1628. [Li H Y, Wang Y H. 2014. Discrete degree on village settlement's spatial distribution and its correlation with net income of rural residents in poverty county[J]. Geographical Research, 33(9): 1617-1628.]

李立勋. 1997. 珠江三角洲乡镇企业发展的地域特征 [J]. 热 带地理, 17(1): 47-52. [Li L X. 1997. The development features of the township enterprises in the Pearl River Delta[J]. Tropical Geography, 17(1): 47-52.]

李新运. 2004. 城市空间数据挖掘方法与应用研究[D]. 青岛: 山东科技大学. [Li X Y. 2004. Research on the method and application of urban spatial data mining[D]. Qingdao, China: Shandong University of Science and Technology.] 李燕, 贺灿飞. 2013. 1998-2009年珠江三角洲制造业空间转 移特征及其机制 [J]. 地理科学进展, 32(5): 777-787. [ $\mathrm{Li}$ Y, He C F. 2013. Characteristics and mechanism of manufacturing industry shift in the Pearl River Delta during 1998-2009[J]. Progress in Geography, 32(5): 777-787.]

申庆喜, 李诚固, 周国否. 2015. 基于工业空间视角的长春市 1995-2011 年城市功能空间耦合特征与机制研究 [J]. 地 理科学, 35(7): 882-889. [Shen Q X, Li C G, Zhou G L. 2015. Coupling characteristics and mechanism of urban functional space of Changchun based on the perspective of industrial space in 1995-2011[J]. Scientia Geographica Sinica, 35(7): 882-889.]

沈静, 向澄, 柳意云. 2012. 广东省污染密集型产业转移机 制: 基于 2000-2009年面板数据模型的实证 $[\mathrm{J}]$. 地理研 究, 31(2): 357-368. [Shen J, Xiang C, Liu Y Y. 2012. The mechanism of pollution- intensive industry relocation in Guangdong Province, 2000- 2009[J]. Geographical Research, 31(2): 357-368.]

王开泳, 陈田. 2008. 珠江三角洲都市经济区地域构成的判 别与分析 [J]. 地理学报, 63(8): 820-828. [Wang K Y, Chen T. 2008. The classification and analysis of areal topology in extended metropolitan area of Pearl River Delta [J]. Acta Geographica Sinica, 63(8): 820-828.]

王青. 2002. 城市形态空间演变定量研究初探: 以太原市为 例 [J]. 经济地理, 22(3): 339-341. [Wang Q. 2002. A quantitative study on the change of urban structure based on Taiyuan City[J]. Economic Geography, 22(3): 339-341.] 王新生, 刘纪远, 庄大方, 等. 2005. 中国特大城市空间形态 变化的时空特征 [J]. 地理学报, 60(3): 392-400. [Wang X S, Liu J Y, Zhuang D F, et al. 2005. Spatial- temporal changes of urban spatial morphology in China[J]. Acta Geographica Sinica, 60(3): 392-400.]

王智勇, 黄亚平, 张毅. 2012. 基于 GIS 的武汉城市工业空间 发展的实证研究 [J]. 华中建筑, (3): 132-138. [Wang Z Y, 
Huang Y P, Zhang Y. 2012. An empirical study of the industrial space development in Wuhan City based on GIS [J]. Huazhong Architecture, (3): 132-138.]

伍世代, 李婷婷. 2011. 海西城市群工业空间格局与演化分 析 [J]. 地理科学, 31(3): 309-315. [Wu S D, Li T T. 2011. Evolution of spatial structure of industry on urban agglomeration in western coastal China[J]. Scientia Geographica Sinica, 31(3): 309-315.]

夏丽丽, 间小培. 2009. 基于重化工业发展的珠江三角洲工业 空间结构演变研究 [J]. 人文地理, 24(6): 68-72. [Xia L L, Yan X P. 2009. A study on the evolution of industrial spatial structure of Pearl River Delta based on the heavy industry development[J]. Human Geography, 24(6): 68-72.] 徐建华. 2002. 现代地理学中的数学方法[M]. 2 版. 北京: 高 等教育出版社. [Xu J H. 2002. Mathematical methods in contemporary geography[M]. 2nd ed. Beijing, China: Higher Education Press.]

许学强, 李邭. 2009. 改革开放 30 年珠江三角洲城镇化的回 顾与展望 $[\mathrm{J}$ ]. 经济地理, 29(1): 13-18. [Xu X Q, Li X. 2009. Review and preview of the urbanization in Pearl River Delta in the past 30 years of reform and opening up [J]. Economic Geography, 29(1): 13-18.]

间小培, 毛蒋兴, 普军. 2006. 巨型城市区域土地利用变化的 人文因素分析: 以珠江三角洲地区为例 [J]. 地理学报, 61(6): 613-623. [Yan X P, Mao J X, Pu J. 2006. Research on the human dimensions of land use changes in the mega-urban region: A case study of the Pearl River Delta [J]. Acta Geographica Sinica, 61(6): 613-623.]

杨涵, 王芳芳, 吴世新, 等. 2009. 基于分形理论的新疆土地 利用空间格局分析 [J]. 干旱区研究, 26(2): 194-199.

[Yang H, Wang F F, Wu S X, et al. 2009. Evaluation of the spatial pattern of land use in Xinjiang in the last 15 years based on fractal theory[J]. Arid Zone Research, 26 (2): 194-199.]

叶昌东, 周春山, 刘艳艳. 2010. 近 10年来广州工业空间分异 及其演进机制研究 [J]. 经济地理, 30(10): 1664-1669. [Ye C D, Zhou C S, Liu Y Y. 2010. The industrial spatial differentiation and its evolution mechanism of Guangzhou in recent ten years[J]. Economic Geography, 30(10): 1664-1669.]

叶玉瑶, 张虹鸥. 2007. 珠江三角洲城市群空间集聚与扩散 [J]. 经济地理, 27(5): 773-776. [Ye Y Y, Zhang H O. 2007. The spatial agglomeration and dispersion in the Pearl River Delta[J]. Economic Geography, 27(5): 773776.]

叶玉瑶, 张虹鸥, 刘凯, 等. 2010. 地理区位因子对建设用地 扩展的影响分析: 以珠江三角洲为例 [J]. 地理科学进 展, 29(11): 1433-1441. [Ye Y Y, Zhang H O, Liu K, et al.
2010. Impact of site factors on expansion of construction land: A case study in the Pearl River Delta[J]. Progress in Geography, 29(11): 1433-1441.]

曾春水, 萄雪芹, 王开泳, 等. 2012. 中国八大经济区工业竞 争力空间格局及投人产出分析 [J]. 地理科学进展, 31 (8): 1005-1012. [Zeng C S, Lin X Q, Wang K Y, et al. 2012. Research on spatial patterns and input-output analysis of industrial competitiveness of economic regions in China[J]. Progress in Geography, 31(8): 1005-1012.]

张文忠, 王传胜, 吕昕, 等. 2003. 珠江三角洲土地利用变化 与工业化和城市化的耦合关系 [J]. 地理学报, 58(5): 677-685. [Zhang W Z, Wang C S, Lv X, et al. 2003. Coupling relationship between land use change and industrialization \& urbanization in the Zhujiang River Delta[J]. Acta Geographica Sinica, 58(5): 677-685.]

赵萍, 冯学智. 2003. 基于遥感与 GIS 技术的城镇体系空间特 征的分形分析: 以绍兴市为例 [J]. 地理科学, 23(6): 721727. [Zhao P, Feng X Z. 2003. Fractal analysis of urban system spatial characteristics based on remote sensing and GIS: A case study of Shaoxing[J]. Scientia Geographica Sinica, 23(6): 721-727.]

Dai J L, Wang K Y, Gao X L. 2010. Spatial structure and land use control in extended metropolitan region of Zhujiang River Delta, China[J]. Chinese Geographical Science, 20 (4): 298-308.

Fan C C, Scott A J. 2003. Industrial agglomeration and development: A survey of spatial economic issues in East Asia and a statistical analysis of Chinese regions[J]. Economic Geography, 79(3): 295-319.

Howland M. 2010. Planning for industry in a post-industrial world: Assessing industrial land in a suburban economy [J]. Journal of the American Planning Association, 77(1): 39-53.

Kuang W H. 2012. Spatio- temporal patterns of intra- urban land use change in Beijing, China between 1984 and 2008 [J]. Chinese Geographical Science, 22(2): 210-220.

Liao H F, Chan R C K. 2011. Industrial relocation of Hong Kong manufacturing firms: Towards an expanding industrial space beyond the Pearl River Delta[J]. GeoJournal, 76(6): 623-639.

Lin G C S. 1997. Red capitalism in South China: Growth and development of the Pearl River Delta[M]. Vancouver, Canada: University of British Columbia Press.

Lindsey C, Mahmassani H S, Mullarkey M, et al. 2014a. Industrial space demand and freight transportation activity: Exploring the connection[J]. Journal of Transport Geography, 37: 93-101.

Lindsey C, Mahmassani H S, Mullarkey M, et al. 2014b. Re- 
gional logistics hubs, freight activity and industrial space demand: Econometric analysis[J]. Research in Transportation Business \& Management, 11: 98-104.

Scott A J. 1982. Locational patterns and dynamics of industrial activity in the modern metropolis[J]. Urban Study, 19(2): 111-141.

Sit V F S. 1998. Hong Kong's “transferred” industrialization and industrial geography[J]. Asian Survey, 38(9): 880904.

Smart A, Hsu J-Y. 2004. The Chinese diaspora, foreign investment and economic development in China[J]. The Re- view of International Affairs, 3(4): 544-566.

Tang B-S, Ho W K O. 2015. Land-use planning and market adjustment under de-industrialization: Restructuring of industrial space in Hong Kong[J]. Land Use Policy, 43: 2836.

Yang C. 2006. Overseas Chinese investments in transition: The case of Dongguan[J]. Eurasian Geography and Economics, 47(5): 604-621.

Zhu J M. 2002. Industrial globalisation and its impact on Singapore's industrial landscape[J]. Habitat International, 26 (2): $177-190$.

\title{
Spatial pattern and morphological characteristics of industrial production space and influential factors in the Pearl River Delta urban agglomeration
}

\author{
DING Jun ${ }^{1,2,3}$, WANG Kaiyong ${ }^{1.2^{*}}$ \\ (1. Institute of Geographic Sciences and Natural Resources Research, CAS, Beijing 100101, China; \\ 2. Key Laboratory of Regional Sustainable Development Modeling, CAS, Beijing 100101, China; \\ 3. University of Chinese Academy of Sciences, Beijing 100049, China)
}

\begin{abstract}
GIS spatial analysis technology provides new path and research perspectives for accurately classifying spatial morphology. Extracting the industrial production space information of the Pearl River Delta region in 2013 through high resolution Google Earth image and summarizing the overall distribution pattern of the industrial production space, this study quantitatively analyzed the morphological characteristics of the industrial production space by introducing the fractal model, compact ratio, discrete degree, and density index, then analyzed the main influencing factors of industrial production space distribution by GIS spatial analysis and statistical analysis tools. The results show that: (1) The total area of industrial production space in the Pearl River Delta region in 2013 was $2604.71 \mathrm{~km}^{2}$. Its spatial distribution presents a typical core-peripheral structure. The industrial production spaces mainly distributed in the flat plain area and formed three spatial distribution models, that is, interlaced, scattered, and concentrated. (2) The industrial production space in the Pearl River Delta urban agglomeration showed clear fractal characteristics, and the fractal dimensions in the core area were smaller than that in the periphery area, but the stability of spatial structure in the core area was higher than that in the periphery area. Among the cities of the Pearl River Delta region, Zhuhai had the highest compact ratio of industrial production space, but Guangzhou had the lowest value; Huizhou had the highest discrete degree of industrial production space, whereas Zhongshan had the lowest value. The scale of each city's industrial production space significant differed, and was positively correlated with economic scale, population, and the number of enterprises. The density index values of Dongguang, Shenzhen, Zhongshan, and Foshan were too high and these cities should promote efficient and intensive use of industrial production spaces. (3) On the basis of a comprehensive analysis, the article concludes that natural environment and traffic conditions, urbanization and economic development zone, policy guidance and regulation, and economic globalization were the main influencing factors of the distribution of industrial production space in the Pearl River Delta urban agglomeration. Key words: industrial production space; spatial morphology; spatial pattern; morphological characteristics; Pearl River Delta urban agglomeration
\end{abstract}

